\title{
Causes and Risk Factors of Hemodialysis Catheter Infection in Dialysis Patients: A Prospective Study
}

\author{
Ebrahim Nasiri (iD ${ }^{1}$, Mohammad Hossein Rafiei ${ }^{2}$, Yusef Mortazavi ${ }^{3}$, Pouya Tayebi ${ }^{4}$ and Mehdi \\ Ghasemzadeh Bariki ${ }^{2, *}$ \\ ${ }^{1}$ Department of Anesthesiology and Operating Room, Faculty of Allied Medical Sciences, Mazandaran University of Medical Sciences, Sari, Iran \\ ${ }^{2}$ School of Allied Medical Sciences, Student Research Committee, Mazandaran University of Medical Sciences, Sari, Iran \\ ${ }^{3}$ Department of Anesthesia and Operating Room, Babol University Of Medical Sciences, Babol, Iran \\ ${ }^{4}$ Department of Vascular and Endovascular Surgery, Rouhani Hospital, Babol University of Medical Sciences, Babol, Iran \\ "Corresponding author: School of Allied Medical Sciences, Student Research Committee, Mazandaran University of Medical Sciences, Sari, Iran. Email: \\ mehdibarikistu@gmail.com
}

Received 2021 July 11; Revised 2021 August 01; Accepted 2021 November 16.

\begin{abstract}
Objectives: Infectious central venous catheter (CVC) complications, including mortality and care and hospitalization costs, are still a major clinical concern. This study aimed to determine the prevalence of hemodialysis catheter infection and its risk factors among hemodialysis patients.

Methods: The present research was a descriptive, prospective cross-sectional study on hemodialysis patients in Babol hospitals during 2020 - 21. The participants' demographic information and some relevant data on clinical variables (namely underlying diseases, cause of dialysis, and cause of catheter removal) and catheter-related variables (namely catheter location, frequency of catheter placement, and apparent signs of catheter site) were collected and recorded directly and systematically during surgery post-surgery. Results: One hundred and twenty-two patients with temporary double-lumen acute hemodialysis catheters for dialysis, including 56 women (45.9\%), were included in this study, the mean age of whom was $58.9 \pm 16.4$ years. Twenty-two patients (18\%) developed a catheter-induced systemic infection. There was no significant relationship between the catheter site and its removal inducing infection $(\mathrm{P}>0.05)$. The frequencies of microorganisms causing catheter infection included gram-positive Staphylococcus epidermis (59\%) and Staphylococcus aureus (31.8\%). Moreover, there was no significant correlation between demographic variables and clinical history with systemic infection induced by catheterization.

Conclusions: The rate of catheter-induced infection is relatively high among patients since sterile instructions were observed during catheterization; therefore, it is recommended to pay more attention to the care and dressing of the catheter site.
\end{abstract}

Keywords: CVC, Renal Failure, Staphylococcus, Venous Access

\section{Background}

Dialysis for end-stage renal disease (ESRD) can be performed by an arteriovenous fistula (AVF) or catheters. However, the catheter usage is associated with an increased risk of all-cause death, mainly due to catheter-related infections (CRI) (1).

Temporary hemodialysis catheters are often associated with early and delayed complications (2), including infection, thrombosis, and torsion. However, infection is the most common complication leading to the removal of temporary catheters. In the fourth week following catheterization, the infection risk is reported to be $10.3 \%$ (3).

The infection complications of CVC, especially mortality rate and general care expenses of septicemia caused by catheterization and hospitalization, are still major clinical concerns (4). CRI has increased the length of hospital stay from 2.4 to 5.7 days with an increasing mortality rate (2). CRI is responsible for 15 - 36\% of all hemodialysis patients' deaths and $20 \%$ of total hospitalizations (5).

The prevalence of bacteremia caused by intravascular devices is significantly increasing. Primary bacteremia from IV catheters now account for half of all primary bacteremia in ICU. Both local and systemic infections can occur following intravascular contamination (2).

Some factors such as long-term usage, the recent history of CRI, recent surgery, diabetes mellitus, and iron overload are the risk factors for catheter infection (6). Grampositive organisms are responsible for most catheter infections. In this regard, infections caused by gram-positive 
bacteria and Staphylococcus aureus account for 40 - $81 \%$ of infections. Methicillin-resistant Staphylococcus aureus is a critical pathogen inducing infection in hemodialysis patients. Other infections are attributed to enterococci and Gram-negative bacteria (7).

\section{Objectives}

Despite efforts to prevent catheter infection in hemodialysis patients, the CVC infection is still one of the main problems among hemodialysis patients. Accordingly, this study aimed to evaluate catheter infection's causes and risk factors in dialysis patients.

\section{Methods}

This prospective, descriptive, and cross-sectional study was performed to evaluate the causes and risk factors for catheter infection in dialysis patients in hospitals affiliated with the Babol University of Medical Sciences during 2020 - 2021. In this research, we examined patients underwent catheterization surgery. Inclusion criteria were patients aged above 18 years, undergoing surgeries to place a Sheldon catheter, and informed consent. Patients willing to be evaluated for symptoms during the research were excluded from the study.

Data were collected and recorded directly and systematically by the researcher during and after surgery using a pre-prepared checklist, which addressed demographic information (namely age, gender, height, weight, and place of residence), clinical variables (i.e., underlying diseases, cause of dialysis, catheter removal, and others), and catheter-related variables (i.e., the site and frequency of catheter insertion and the appearance of catheter site). All procedures performed during catheter placement were also recorded. The patients took part in the study after being informed of the research objectives and submitting their informed consent.

All patients underwent catheterization surgeries with a three-way catheter (Arrow Multi Lumen Catheter) in the operating room under similar conditions of local anesthesia (lidocaine). The preparation and disinfection of the operation area were done using Povidone-Iodine solution (10\% Toluidine, manufactured by Toliddaru Company, Iran). The surgeries were performed with the full observance of the principles of sterility with gown and gloves and full cap and disposable plastic combs in the surgical area. Finally, the skin of the operation area was sutured with 0.3 or 0.4 nylon suture and covered with sterile gauze. During treatment, patients were routinely monitored, and standard treatments were provided to all patients.
The patients were followed up until the catheter was removed. The catheter was taken away for different reasons, including recovery, catheter dysfunction, suspected infection, or death. Follow-up was also stopped when each patient was discharged with a catheter to continue treatment in the hemodialysis clinic. If the infection symptoms were observed, to diagnose the cause of infection and the type of bacterium, $3-5 \mathrm{~cm}$ from the end of the catheter was transferred to a laboratory unit in a sterile container by observing relevant principles to have the necessary cultures (i.e., the culture of the interior and tip of catheter). The test results and the types of bacteria were recorded in a checklist.

Statistical analysis was performed using SPSS software version 21. Chi-square test and Fisher's exact test were run for qualitative variables, and t-test was used for quantitative variables. In this study, $\mathrm{P}<0.05$ was set as the level of significance.

\section{Results}

In this study, 122 patients, who had undergone temporary double-lumen acute hemodialysis catheters in the operating room for dialysis, were selected, among whom there were 56 women (45.9\%) and 66 men (54.1\%). The participants' mean age was $58.9 \pm 16.4$ years (range: 19 - 95 years). The highest prevalence of the underlying disease among dialysis patients was cardiovascular disease (CVD) (76.2\%). Figure 1 presents the prevalence of underlying diseases.

Catheters were removed from 22 patients (18\%) due to infections. There was no significant relationship between the catheter site and its removal inducing infection $(\mathrm{P}>$ 0.05). The types of the organism obtained from the inside and tip of the catheter were Staphylococcus epidermis in 13 patients (59.1\%), Staphylococcus aureus in seven patients (31.8\%), Klebsiella pneumoniae in one patient, and Escherichia coli in one patient. No significant relationship was noticed between the catheter insertion site and the type of bacteria $(P>0.05)$. In a review of the clinical infection signs, the clinical signs of catheter infection were redness at the catheter insertion site in 13 patients (10.7\%) and the discharge of pus in five patients (4.1\%). In total, only four patients (3.1\%) had both redness and pus at the catheter site.

The catheter of 24 patients (19.7\%) was removed due to temporary double-lumen acute hemodialysis catheter dysfunction (caused by blood clotting inside the catheter). There was no significant relationship between the catheter site and its removal inducing catheter dysfunction $(\mathrm{P}>$ 0.05). Table 1 shows the frequency of different catheter sites and the reason for catheter removal. 


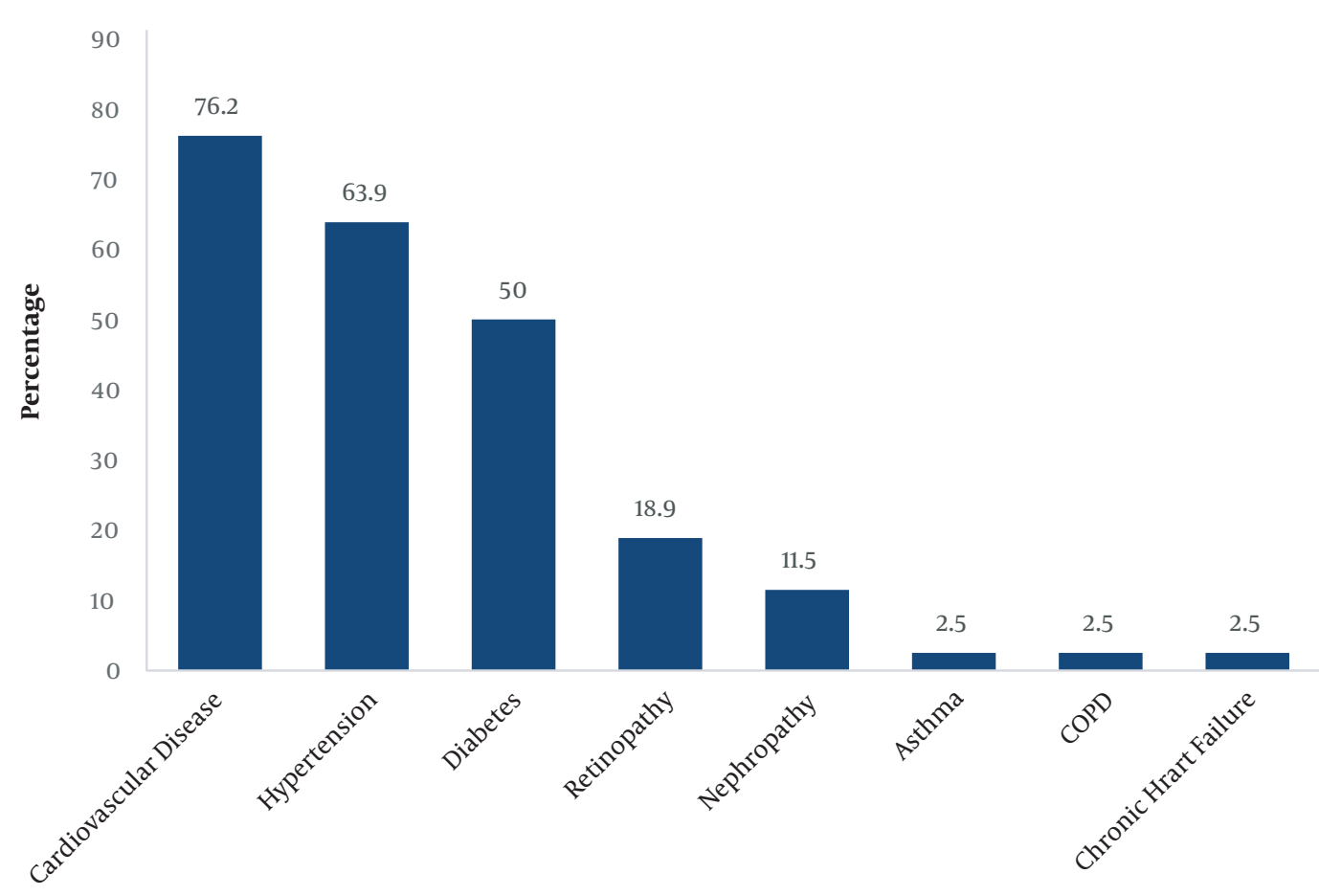

Figure 1. Frequency of underlying diseases

\begin{tabular}{|c|c|}
\hline Variables & No. (\%) \\
\hline \multicolumn{2}{|l|}{ Catheter site } \\
\hline Subclavian & $59(48.4)$ \\
\hline Jugular & $54(44.3)$ \\
\hline Femoral & $9(7.4)$ \\
\hline \multicolumn{2}{|l|}{ Reason for removal } \\
\hline $\begin{array}{l}\text { Infection during temporary double-lumen acute } \\
\text { hemodialysis catheter use }\end{array}$ & $22(18)$ \\
\hline $\begin{array}{l}\text { Temporary double-lumen acute hemodialysis catheter } \\
\text { dysfunction }\end{array}$ & $24(19.7)$ \\
\hline Replacement to insert permcath catheter & $33(27)$ \\
\hline
\end{tabular}

There was no relationship between gender, age, body mass index, place of residence, and the number of dialysis sessions per week with an infection. However, among the infected individuals in this study, there were more men than women, with most of the patients aged $<45$ years old and with BMI > 30 (Table 2 ).

The relationship between infection during catheter use and underlying diseases was not significant. Only the prevalence of underlying diseases of diabetes, hyper- tension, and CVD was higher among the infected. There was no correlation between different causes of catheterization with infection. Only people who had catheterization caused by high blood pressure and cardiovascular patients were more likely to become infected by catheter insertion (Table 3).

\section{Discussion}

The findings showed that the total prevalence of systemic catheter infection among dialysis patients was $18 \%$. In different studies, 1.6 - $67 \%$ of catheterizations in dialysis patients has induced systemic catheter-induced infection (8). The CRI rates were $11 \%$ in Afshar et al.'s study in Kashan with a sample size of 43 patients (9), 5\% in AdibHajbagheri's study in Isfahan with a sample size of 38 (10), and 78\% in Sanavi et al.'s (11) study in Tehran with a sample size of 116 patients.

The inconsistencies in the findings of this study and those of the previous studies could be caused by the differences in study setting and time, as well as and patient variables. Differences in catheter care behaviors, catheter type, or placement time may also affect the outcomes (4). 
Nasiri E et al.

\begin{tabular}{|c|c|c|c|c|}
\hline \multirow{2}{*}{ Variables } & \multicolumn{2}{|c|}{ Infection } & \multirow{2}{*}{ P-Value } & \multirow{2}{*}{ Test Statistic } \\
\hline & Yes & No & & \\
\hline Gender & & & 0.14 & 2.14 \\
\hline Female & 7 & 49 & & \\
\hline Male & 15 & 51 & & \\
\hline Age & & & 0.07 & 3.15 \\
\hline$<45$ & 8 & 19 & & \\
\hline$>45$ & 14 & 81 & & \\
\hline BMI & & & 0.51 & 0.37 \\
\hline$<30$ & 16 & 82 & & \\
\hline$>30$ & 4 & 14 & & \\
\hline Residence & & & 0.67 & 0.17 \\
\hline Village & 11 & 55 & & \\
\hline City & 11 & 45 & & \\
\hline Dialysis times per week & & & 0.69 & 0.84 \\
\hline $1-2$ & 1 & 11 & & \\
\hline$>2$ & 21 & 89 & & \\
\hline
\end{tabular}

In different studies, the infection of the catheter site is reported to range from 4 to $15 \%$. In the present study, local infection was observed in $3.1 \%$ of the patients. In general, in catheter-related infections, local infection, even in the presence of septicemia, is less common (12). However, this study's lower infection rate may be due to the limited definition of catheter site infection in this research.

Similar to the present study, previous investigations have revealed the 40-80-percent CRI functions of grampositive bacteria $(13,14)$. In this research, gram-positive bacteria of Staphylococcus epidermis (59\%) followed by Staphylococcus aureus (31.8\%) were the most common microorganisms causing catheter infection. In many studies, there are different organisms, including Staphylococcus aureus accounting for 3 - 74\% of infections, and Staphylococcus epidermis, inducing $7-42 \%$ of systemic infections (13).

Accordingly, most of the microorganisms in the catheter are part of the skin's natural flora. Gram-positive bacteria are responsible for at least two-thirds of these infections. In temporary catheter infections, catheter colonization is usually (75 - 90\% of cases) the result of microorganisms migrating from the tip of the catheter into a blood vessel. This observation indicates that the principles of sterility adopted during catheterization, dressings, and skin disinfection during the care procedures in this site can significantly affect the incidence of these infections (15). Due to the prospective nature of this study, the researchers spared efforts to fully observe the principles of sterility for catheter placement. Given the temporary nature of these catheters and the fact that they remain in place for a maximum of two weeks, the transmission of infection from the skin to the tip of the catheter can be caused by the dressing care of the catheter site during these two weeks.

Studies have indicated that femoral catheters should be avoided, if possible because they cause more infectious and thrombotic complications compared to the internal jugular and subclavian catheters. They are also associated with a higher rate of deep vein thrombosis (16). However, no relationship was noticed between catheter site and infection in this study. Regarding concerns about catheter dysfunction and the increased risk of infection, femoral catheters are usually less preferred than internal jugular catheters. However, in line with the findings of this research, several studies have not reported a significant relationship between the catheterization site and infection $(6,17)$. Cathedia randomly selected 750 patients from 12 different intensive care units to place an internal femoral or jugular catheterization and documented a similar infection rate between femoral and internal jugular access (18). There was no significant correlation between infectious complications and catheter failure with catheter placement in different studies. Some studies have reported a higher infection risk of internal jugular access (3, 8-10).

In this study, the CRI risk was not correlated with the patient's age, gender, diabetes, vascular disease, heart failure, and blood pressure. This finding was consistent with several other studies $(11,13)$.

According to the findings of this study, gender does not predict CRI. Shirotani et al., Coker et al., and Mohammadkarimi et al.'s studies also documented no relationship between gender and CRI $(19,20)$.

Poinen et al. found out that elderly patients accounted for about one-third of all circulatory infections induced by CVC; however, age was not a consistent predictor of the infection risk. Statistically, age was not associated with the incidence of infection (21). However, in this study, younger 
Nasiri E et al.

\begin{tabular}{|c|c|c|c|c|}
\hline \multicolumn{5}{|c|}{ Underlying Disease } \\
\hline \multirow{2}{*}{ Variables } & \multirow{2}{*}{ Test Statistic } & \multirow{2}{*}{ P-Value } & \multicolumn{2}{|c|}{ Infection } \\
\hline & & & No & Yes \\
\hline \multicolumn{5}{|l|}{ Diabetes } \\
\hline Yes & 0.51 & 0.47 & 40 & 7 \\
\hline No & & & 60 & 15 \\
\hline \multicolumn{5}{|c|}{ Nephropathy } \\
\hline Yes & 1.70 & 0.22 & 3 & 2 \\
\hline No & & & 97 & 20 \\
\hline \multicolumn{5}{|c|}{ Retinopathy } \\
\hline Yes & 0.48 & 0.45 & 2 & 1 \\
\hline No & & & 98 & 21 \\
\hline \multicolumn{5}{|c|}{ Hypertension } \\
\hline Yes & 1.00 & 0.31 & 66 & 12 \\
\hline No & & & 34 & 10 \\
\hline \multicolumn{5}{|l|}{ CVD } \\
\hline Yes & 0.48 & 0.45 & 2 & 1 \\
\hline No & & & 98 & 21 \\
\hline \multicolumn{5}{|l|}{ Asthma } \\
\hline Yes & 0.99 & 0.29 & 4 & 2 \\
\hline No & & & 96 & 20 \\
\hline \multicolumn{5}{|c|}{ Reason for Catheterization } \\
\hline \multicolumn{5}{|l|}{ Diabetes } \\
\hline Yes & 0.88 & 0.34 & 59 & 9 \\
\hline No & & & 48 & 13 \\
\hline \multicolumn{5}{|c|}{ Transplant rejection } \\
\hline Yes & 0.12 & 0.71 & 11 & 3 \\
\hline No & & & 89 & 19 \\
\hline \multicolumn{5}{|c|}{ Renal stone } \\
\hline Yes & 0.00 & 0.99 & 19 & 4 \\
\hline No & & & 81 & 18 \\
\hline \multicolumn{5}{|c|}{ Hypertension } \\
\hline Yes & 1.02 & 0.31 & 66 & 12 \\
\hline No & & & 34 & 10 \\
\hline \multicolumn{5}{|c|}{ Hereditary } \\
\hline Yes & 2.34 & 0.12 & 79 & 14 \\
\hline No & & & 21 & 8 \\
\hline \multicolumn{5}{|c|}{ Polycystic kidney } \\
\hline Yes & 0.67 & 1.00 & 3 & 0 \\
\hline No & & & 97 & 22 \\
\hline
\end{tabular}

ages increased the infection risk to some extent. In their studies, Bozzetti et al. and Murea et al. report that older people are less likely to develop infection $(22,23)$.

Hypertension is introduced as a risk factor in different studies $(24,25)$. Despite the impact of high blood pressure on CRI, it revealed no statistically significant effect. Pawar et a. and Hussein et al. also found no relationship between high blood pressure and CRI $(8,14)$.

In some studies (e.g., Lemaire et al. \& Wang et al.), diabetes is reported as a risk factor for CRI $(6,24)$. A closer look at these studies suggests that catheter infection in diabetic patients may be a function of long-term usage of a catheter in such patients. However, in the long-term use of tempo- rary catheters instead of venous, arterial fistulas can lead to infection, even in non-diabetic patients.

There was no significant relationship between the history of cardiovascular disease and CRI; however, the prevalence of infection was higher among cardiovascular patients. Marcos et al. and Fram et al. also detected no association between CRI and CVD $(26,27)$.

The variety of etiological factors or follow-up time affects the frequency of risk factors reported in different centers (7).

\subsection{Limitations}

This study had several limitations. First, the patients revealing no clinical septicemia were not tested for blood 
infections. Second, this study was performed during the COVID-19 pandemic, which could have affected the results. And finally, the other limitations of this study were not following up the dressings and not taking care of the catheter during the catheter usage time were. Accordingly, future researchers are recommended to consider this point in future prospective studies.

\subsection{Conclusion}

The CRI rate is relatively high among patients in Babol medical-teaching centers, who had undergone hemodialysis; however, sterile instructions were observed during the catheterization. The pattern of pathogenic catheter microorganisms observed in this study was similar to other studies, and the gram-positive bacteria of Staphylococcus epidermis and Staphylococcus aureus, which are the natural flora of the skin, induced systemic infection in the catheter. Attempts were made to observe the principles of sterility for catheters in this study as such, the transfer of bacteria from the skin to the tip of the catheter may be a function of care and dressings performed during the catheter usage. The findings indicated no relationship between the catheter site and the incidence of infection. Clinical history and patients' diseases were not associated with systemic catheter infection.

\section{Footnotes}

Authors' Contribution: M. G. B. and E. N. did overall supervision, material provision, study conception. P. T. and M. G. B. collected the required data. M. H. R. statistically analyzed the data and helped in data provision. Y. M., E. N., and M. G. B. prepared the manuscript, had final editing, and put forth the study conception.

Conflict of Interests: No, there are no competing interests for any author.

\section{Ethical Approval: IR.MAZUMS.REC.1398.1402}

Funding/Support: No funding was obtained from any organization.

Informed Consent: The patients took part in the study after being informed of the study objectives and obtaining their informed consent.

\section{References}

1. Bohlke M, Uliano G, Barcellos FC. Hemodialysis catheter-related infection: prophylaxis, diagnosis and treatment. J Vasc Access. 2015;16(5):347-55. doi: 10.5301/jva.5000368. [PubMed: 25907773].

2. Tavanaee Sani A, Eslami Nowkandeh AR, Ghorbany H. Central venous catheter-related infection among patients on hemodialysis. Med J Mashad Univ Med Sci. 2012;55(2):110-5.
3. Oliver MJ, Callery SM, Thorpe KE, Schwab SJ, Churchill DN. Risk of bacteremia from temporary hemodialysis catheters by site of insertion and duration of use: a prospective study. Kidney Int. 2000;58(6):25435. doi: 10.1046/j.1523-1755.2000.00439.x. [PubMed: 11115089].

4. Karimian M, Afsharloo S, Mandikhani S, Salimi E, Borj M, Tarjoman A, et al. Prevalence of central venous catheter infections in hemodialysis patients. J Med Sci. 2020;24(104):2555-9.

5. Hemmati H, Safayiasl A, Badrangbuye S, KazemnezhadLeyli E, Poursafar MZJ. [Central venous catheter infections in hemodialysis patients]. J Guilan Univ Med Sci. 2018;27(105):20-7. Persian.

6. Sahli F, Feidjel R, Laalaoui R. Hemodialysis catheter-related infection: rates, risk factors and pathogens. J Infect Public Health. 2017;10(4):4038. doi: 10.1016/j.jiph.2016.06.008. [PubMed: 27423929].

7. Hadian B, Zafarmohtashami A, Razani M. Catheter-related blood stream infections in hemodialysis patients. J Renal Inj Prev. 2020;9(4):e34. doi: 10.34172/jrip.2020.34.

8. Pawar M, Mehta Y, Kapoor P, Sharma J, Gupta A, Trehan N. Central venous catheter-related blood stream infections: incidence, risk factors, outcome, and associated pathogens. J Cardiothorac Vasc Anesth. 2004;18(3):304-8. doi: 10.1053/j.jvca.2004.03.009. [PubMed: 15232809].

9. Afshar M, Savari F, Adib-Hajbagheri M, Gilasi HR, Soleimani A, Baseri $\mathrm{AM}$, et al. [Permanent hemodialysis catheter complications in patients referred to Kashan Akhavan dialysis center from June 2013 to December 2013]. KAUMS Journal (FEYZ). 2015;19(2):162-8. Persian.

10. Adib-Hajbagheri M, Molavizadeh N, Alavi NM, Abadi MH. Factors associated with complications of vascular access site in hemodialysis patients in Isfahan Aliasghar hospital. Iran J Nurs Midwifery Res. 2014;19(2):208-14. [PubMed: 24834093]. [PubMed Central: PMC4020033].

11. Sanavi S, Ghods A, Afshar R. Catheter associated infections in hemodialysis patients. Saudi J Kidney Dis Transpl. 2007;18(1):43-6. [PubMed: 17237890].

12. Lorente L, Henry C, Martin MM, Jimenez A, Mora ML. Central venous catheter-related infection in a prospective and observational study of 2,595 catheters. Crit Care. 2005;9(6):R631-5. doi: 10.1186/cc3824. [PubMed: 16280064]. [PubMed Central: PMC1414031].

13. Farrington CA, Allon M. Management of the Hemodialysis Patient with Catheter-Related Bloodstream Infection. Clin J Am Soc Nephrol. 2019;14(4):611-3. doi: 10.2215/CJN.13171118. [PubMed: 30837242]. [PubMed Central: PMC6450352].

14. Hussein WF, Mohammed H, Browne L, Plant L, Stack AG. Prevalence and correlates of central venous catheter use among haemodialysis patients in the Irish health system - a national study. BMC Nephrol. 2018;19(1):76. doi: 10.1186/s12882-018-0873-x. [PubMed: 29609535]. [PubMed Central: PMC5880000].

15. Sadoyma G, Diogo Filho A, Gontijo Filho PP. Central venous catheterrelated bloodstream infection caused by Staphylococcus aureus: microbiology and risk factors. Braz J Infect Dis. 2006;10(2):100-6. doi: 10.1590/s1413-86702006000200006. [PubMed: 16878260].

16. Bell T, O'Grady NP. Prevention of Central Line-Associated Bloodstream Infections. Infect Dis Clin North Am. 2017;31(3):551-9. doi: 10.1016/j.idc.2017.05.007. [PubMed: 28687213]. [PubMed Central: PMC5666696].

17. Mahotra NB, Sapkota A, Sedhain A. Hemodialysis Catheter-Related Infection in a Teaching Hospital of Central Nepal. J Inst Med Nepal. 2019;41(2):11-6. doi:10.3126/jiom.v41i2.26541.

18. Parienti JJ, Thirion M, Megarbane B, Souweine B, Ouchikhe A, Polito A, et al. Femoral vs jugular venous catheterization and risk of nosocomial events in adults requiring acute renal replacement therapy: a randomized controlled trial. JAMA. 2008;299(20):2413-22. doi: 10.1001/jama.299.20.2413. [PubMed: 18505951].

19. Shirotani N, Iino T, Numata K, Kameoka S. Complications of central venous catheters in patients on home parenteral nutrition: an analysis of 68 patients over 16 years. Surg Today. 2006;36(5):420-4. doi: 10.1007/s00595-005-3179-0. [PubMed: 16633748]. 
20. Mohammadkarimi V, Anushiravani A, Adibi S, Dalfardi B. Catheter Infection Among Hemodialysis Patients: A Report From Fars Province, Iran. Avicenna J Clin Microbiol Infect. 2020;7(2):45-9. doi: 10.34172/ajcmi.2020.10.

21. Poinen K, Quinn RR, Clarke A, Ravani P, Hiremath S, Miller LM, et al. Complications From Tunneled Hemodialysis Catheters: A Canadian Observational Cohort Study. Am J Kidney Dis. 2019;73(4):467-75. doi: 10.1053/j.ajkd.2018.10.014. [PubMed:30642607].

22. Bozzetti F, Mariani L, Bertinet DB, Chiavenna G, Crose N, De Cicco $\mathrm{M}$, et al. Central venous catheter complications in 447 patients on home parenteral nutrition: an analysis of over 100.000 catheter days. Clin Nutr. 2002;21(6):475-85. doi: 10.1054/clnu.2002.0578. [PubMed: 12468367].

23. Murea M, James KM, Russell GB, Byrum G3, Yates JE, Tuttle NS, et al. Risk of catheter-related bloodstream infection in elderly patients on hemodialysis. Clin J Am Soc Nephrol. 2014;9(4):764-70. doi: 10.2215/CJN.07710713. [PubMed: 24651074]. [PubMed Central: PMC3974362].

24. Lemaire X, Morena M, Leray-Moragues H, Henriet-Viprey D, Che- nine L, Defez-Fougeron C, et al. Analysis of risk factors for catheterrelated bacteremia in 2000 permanent dual catheters for hemodialysis. Blood Purif. 2009;28(1):21-8. doi: 10.1159/000210034. [PubMed: 19325236].

25. Menegueti MG, Betoni NC, Bellissimo-Rodrigues F, Romao EA. Central venous catheter-related infections in patients receiving shortterm hemodialysis therapy: incidence, associated factors, and microbiological aspects. Rev Soc Bras Med Trop. 2017;50(6):783-7. doi: 10.1590/0037-8682-0438-2017. [PubMed: 29340455].

26. Fram D, Okuno MF, Taminato M, Ponzio V, Manfredi SR, Grothe C, et al. Risk factors for bloodstream infection in patients at a Brazilian hemodialysis center: a case-control study. BMC Infect Dis. 2015;15:158. doi: 10.1186/s12879-015-0907-y. [PubMed: 25879516]. [PubMed Central: PMC4377039].

27. Marcos M, Soriano A, Inurrieta A, Martinez JA, Romero A, Cobos $\mathrm{N}$, et al. Changing epidemiology of central venous catheterrelated bloodstream infections: increasing prevalence of Gramnegative pathogens. J Antimicrob Chemother. 2011;66(9):2119-25. doi: 10.1093/jac/dkr231. [PubMed: 21665905]. 